\title{
Professional English Communication for Engineers in Nepal
}

\author{
Santosh Agrawal \\ PhD Scholar, Mewar University, Rajasthan, India \\ E-mail: nepalsa71@gmail.com
}

\begin{abstract}
This article is focused on the nature, needs and problems of the professional communications of the engineers in Nepal. It includes a number of significant aspects of the engineering professional communication with the use of English language. The study is an outcome of a survey of several aspects of the engineering profession, study of several relevant literature and the contact to a number of experts associated with the field of professional communication. The researchers in the field of professional communication require being more and more specific according to the changing specific needs of the professionals in the modern context today. It is necessary to pinpoint the nature of engineering professional skills, in order to save the time and other resources, if they are not properly utilized to achieve the set goals. The researchers in the past along with the students over here, are aware of the necessity of making more and more researches in the field of professional communication of the engineers in order to minimize the communicative problems of the engineers on one hand and to show a proper and adequate specific path in the areas of teaching and learning the specific skills of communication on the other. The sole purpose of the present research article is to indicate a number of measures to be applied to better the communicative situations of the engineers both during their study and at work. Hence a number of tentative suggestions and recommendations have been drawn following the conclusion of the article.
\end{abstract}

KEYWORDS: English communication, Professional, Engineers, Nepal

\section{INTRODUCTION}

Communication is the backbone of social, educational as well as corporate scenario in the world today. It maintains our existence in the globe. Evidence indicates that communication skills are what helped Homo sapiens evolve beyond our related ancestors, and that these skills have helped humankind develop into the advanced societies on Earth today (Tattersall, 2000). The ever growing need for effective communication skills in English has created a huge demand for learning quality English around the world. There is ample evidence that graduate engineers lack the required standard of communication skills, particularly when compared to the needs of industry internationally (Jensen, 2000) (Grünwald N. , 1999). A number of scholars have been involved in studying the English communications of various professionals including Engineers, medical doctors and business personalities. Attempts on studying the communicative skills of 
engineers have been all the more popular. The present article is directed towards this goal. The focus of attention of this article is on the nature of communication in the field of Engineering with a view to highlighting the problems and the solutions thereafter.

"A global engineer must be able to easily cross national and cultural boundaries. This in turn directly affects engineering education. A common code for communication is required. Those education institutions, which meet the language requirements for the new global engineer, will be ready to face the new millennium" (Riemer, 2002).

According to Reimer an Engineer is a global personality and therefore he/she must be able to easily cross national and cultural boundaries. This in turn directly affects engineering education. A common code for communication is required. Those education institutions, which meet the language requirements for the new global engineer, will be ready to face the new millennium. In the present global context a study of English language communication of the engineers in Nepal is highly preferable.

As mentioned previously, the sole intention of the present article is to highlight the nature of communication prevalent in the field of Engineering, the role of communication for the Engineers, and the tentative suggestions and recommendations towards it. If the engineers lack adequate quantity of English language related to their field of engineering, they cannot communicate engineering skills and ideas to a desired extent. Nor they can properly grasp the technique of engineering without this quality. Moreover they lack the communicative skills to express their findings if any, in international journals, to be properly expressed to the world outside.

There is ample evidence that graduate engineers lack the required standard of communication skills, particularly when compared to the needs of industry internationally (Jensen, 2000) (Grünwald N. , 1999). As we are in the global scenario with rapidly growing uses of science and technology that requires all the time development of various types of software along with the hard ones to cope with the growing need of newer and newer technology to upgrade the lifestyle of the human race, the specific use of English language for specialized engineering field is obviously inevitable. English is cited as the ..."major language of international business, diplomacy, and science and the professions" (Kitao, 1996)).

It is a common place to mention here that English is a source language for all modern development programs and practices in a number of fields of engineering namely engineering media network, various websites, formulation of engineering instruction materials and production of many other engineering related programs and materials, along with a number of modern electrical appliances (Grünwald $\mathrm{N}$. a.). In a sense a good engineer requires to be equipped with adequate communicative skills to use international journals, periodicals and to be able to publish research articles on current engineering affairs on the way to accomplishing 
engineering job/s smoothly. Precisely speaking, a good Engineer is inevitably a good communicator.

\section{METHOD}

In order to complete the present article a specific methodology has been used. The methodology thus used is concentrated on the professional communication skills of the Engineers at different strategic points- During study, at work and during the need of updating the engineering skills along with necessary skills required for the publication of the findings of the engineers at times. Their representative samples of communication in their respective fields have been taken into consideration in order to accomplish the task of writing the present article. At the same time, several books, journals and internets have also been consulted in order to bring the article into completion. The relevant points from the study and the findings obtained from it have been included in the following sub titles, along with the summary conclusion and the tentative suggestions to the authorities concerned.

\section{RESULT \& DISCUSSION}

\section{A) Nature and significance of professional communication in English}

Among the very few significant fields of study today, engineering has become all the more popular. In the present context of the globe the skills and ideas in Engineering are communicated mainly with the use of English language. The engineers are bound to be proficient in the engineering aspects of this language through a number of ways. For this they require to study English language with the use of various resources including the language laboratories and several other relevant practices, besides the common practices of learning. This maybe the reason why employers want: ...

"a number of new competencies, with an emphasis on an increased ability to communicate"... and good foreign language skills (Jensen, 2000)

Engineers require learning communicative skills of the language relevant to their specific field of engineering on one hand and they must not forget to repair and maintain their basic level of their language on the other hand. In the context of learning engineering knowledge and practices, the engineering students need to perform their activities in several aspects. They require dealing with a number of lectures, engineering projects, and paper presentation; talk giving, conduction of meetings, and writing proposals of several types. An Engineer in Nepal all the time requires competing with the engineers in the world outside; they cannot remain simply as the engineers in Nepal alone. To quote; 
According to (K.Latha, 2014), to be victorious in any field one needs to know and understand how to communicate effectively. In the era of LPG (Liberalization, Privatization and Globalization), good communication expertise are the keys to unlock the doors of success.

Therefore, an Engineer is an international personality. This is the major reason why they strictly need to be proficient in English, related to their fields of Engineering, both in and outside the country.

Learning English is not an easy task, as the term English itself is something like a vast ocean. There are several aspects of the language. Different professionals require different aspects of the same language to smoothly carry on their profession. Medical professionals for example require the medical brand of the English language whereas the business people require the different aspect of it. In the same way scientists require to choose the scientific brand of English language for their given purposes, similarly technicians of various types are bound to choose their respective brand of technical English to proceed smoothly in their technical scenario. This is the major purpose why the engineers in Nepal require choosing their own aspects of the language in their own specific field. The engineers need to choose the scientific and technical brand of the English language rather than others. Even within the scientific and technical brand of English language they require to be more specific as per the specific requirement of their profession. In a sense they need to choose the engineering brand of English language even within the broad area of science and technology to smoothly carry on their profession. These are the reasons why; The concept of ESP achieves more in the education of engineering students by focusing the learner's attention on the particular terminology and communication skills required in the professional field. Various examples in the engineering field can be found, including computer science, maritime engineering's sea speaks, aviation's air speaks and the railway's rail speaks" (Riemer, 2002).

All these facts indicate the higher significance of the professional communication of the English language in a popular field like that of engineering. Precisely speaking, engineers today require using English for engineering purposes in general and English for specific purposes in particular.

\section{B) Engineering profession and role of English}

The field of engineering is one of the aspects of the applied science but it has gained a broader status in the globe today, including that of engineering (Kitao, 1996)). A number of specific fields within the broader field of engineering, fields like civil engineering, Electrical engineering, electronics engineering, Industrial engineering, mechanical engineering, chemical engineering and computer engineering can be mentioned here among several others. The communication technique of one field of engineering differs from the others according to the nature and purpose of the profession. For instance the nature and profession of electronics engineers are different from those of the others. The purpose of the present article here is to highlight the broader role of the English language for the engineering profession in general. Researches on specific brand of 
English communication for specific fields of engineering profession cannot be ignored in the modern context of the world; the researchers in future can explore the specific brands as per their specific need of the research.

The role of English language is in a way connected with the ESP (English for specific purposes) approach, very popular movement in the globe today. As English language is used for various purposes, the purpose of using this language in the field of science and technology has gained a newer specific status termed EST (English for science and technology), a subfield within the field of ESP. The field of science and technology is also very broad today. Fields like general science, like medicines and engineering fall under this broader aspect of science and technology. In other words the nature of communication of the engineers in English must be EST for engineering in general. As the specialized context today demands specialized Brand of communication technique for the specific field of engineering, the EST for engineering also requires to be specified according to the demands of the specific fields of engineering. As stated earlier the role of English language for engineers requires being English for engineering purposes (EEP) in general and English for specific engineering purposes in particular. According to (K.Latha, 2014), "English communication competence plays an important role in the academic life and career of engineering students".

In order to proceed smoothly in the field of engineering in Nepal as well as world outside, the engineers are bound to be proficient in the use of professional communication in English with adequate improvement in the basic foundation of the language. As mentioned earlier, a good engineer is always good in engineering communication. S/he requires being skillful in the use of the engineering communication skills of the language during the study period in the beginning and at work in future. Without proper and adequate use of the engineering professional communicational skills of the English language in a country like ours, no engineer can smoothly move in his/her profession. All the engineers whether they are in one specific field or the other need to be proficient in the professional communications in accordance with the specific field of the profession. The Engineering profession cannot move without proper and adequate role of professional communication skills of the English language in the context of Nepal.

\section{C) Communicative Problems in the field of engineering}

It is known from the study that in a country like Nepal the use of English in the field of engineering is not specific to a desired extent. The nature of communication skills imparted to them is very general. Out of several engineering fields visited, above seventy five percent of the communication skills of the engineers are not found up to the mark. Even the institute for learning engineering communication with the use of English is found to be less effective for the engineers. 
In fact engineers required to use their professional communication at some given strategic points- during study, at work, for updating engineering skills and ideas and for publishing their findings. In a word engineers in a country like Nepal face a number of challenges in terms of communication both in and outside the country. They lack proper and adequate skills of communication needed for being a global engineering personality. It is also learned from the visits in connection with the engineering institutes, Engineering sites, workshops, and engineering consultancies that the English communication exposure to the engineers is found to be almost not to the desired level. They require updating their professional com (Roulston, 1992)munication in English with their own personal efforts too. Oral communication plays a vital role to advance in the other aspects of the engineering professional communication as in the following words;

"Another significant element included the lack of opportunity for engineering students to be able to practice communication skills, particularly the oral component" (Roulston, 1992).

In reality the students in the engineering fields lack oral communication rather than others.

A study of the professional communications of the engineers prevailing at the institutes of engineering indicates a number of factors in relation to it. The standard and nature of the curriculum are seen to be updated frequently in spite of some lacking, like the inclusion of less relevant reading materials, inadequate preparation of the atmosphere for learning professional communication and inadequate teacher preparation, less effective use of language laboratories and inadequate use of evaluation procedures. Moreover most of the classes including science and engineering are found to be wrong using Nepalese languages.

A general survey of the engineering consultancies and projects has indicated that the professional English language communication atmosphere is less effective for the engineers to compete with the international projects. The level of professional communication to correspondence and talk giving and also paper writing has been found to be not so satisfactory. In a sense the engineers in Nepal have been facing a number of problems and challenges in their professional carrier with inadequate level of their professional communication skills.

\section{Measures being applied minimizing the communication problems of the Engineers.}

So far it is found from the study that the professional communication skills, learning atmosphere in the institutes, consultancies and engineering firms are being only slightly improved. The language laboratories with the improvement in the professional communication learning environment are being installed and the laboratories already established are also being improved with the communicative needs of the learners in the respective fields of Engineering in spite of the lacking in adequate and proper use of them. It is also learned that the professional communication training environment has also been prepared in the consultancies and the 
engineering firms, in spite of some more lacking, such as the environment for making researches as per the prevailing needs.

\section{Summary}

The modern age is highly connected with the skills of communication in a number of fields. Various professionals require various aspects of professional communication in English. The profession of engineering is really popular in the globe today. The path of development can be seriously blocked without the engineering skills today. A country like Nepal cannot proceed further without proper and adequate development in the sector of engineering. The field of engineering cannot develop without proper and adequate use of English. For this the professional communication learning environment for the engineers for their respective fields and sub fields need to be prepared and developed. In a word the learning of professional communication is mainly from the institute of Engineering. The learning of professional communication requires to be based on some given aspects of English language. The aspect is based mainly on ESP approach directed to the field of science and technology i.e. with EST for Engineering. From the study it is learned that the professional communication learning environment in the institutes, consultancies and firms, is being improved day by day, though with some lacking as well. Although there are a number of problems in learning and using professional communications for the professionals in Nepal the realization of the significance of professional communication in the field of engineering is evident to some extent. It is seen that Language training inspiration and language learning environment are being enhanced in the fields of engineering in Nepal.

\section{CONCLUSION}

The importance of professional communication for various professionals cannot be exaggerated today. The professional communication in the field of engineering cannot stand as an exception to this reality. Engineers require being proficient in using engineering communication with the use of English language. Engineering communication is none other than the use of Basic English with a view to molding it to the respective field of Engineering with adequate and proper enhancement, in it. The professional communication learning environment in the fields of engineering from the engineering institutes down to the engineering sites seem not to reach the desired level yet. The authorities and all the other people concerned require paying more attention towards it.

\section{Suggestion/Recommendation}

On the basis of the conclusion drawn in this article, the following suggestions /recommendations can be forwarded for necessary improvement in promoting the professional communication learning and using in the fields of engineering in Nepal.

1. The professional communication learning environment in the institutes of engineering is further improved according to the changing needs of the engineers today. 
2. Concerned researchers in the field of communication techniques be given due regards to enhance the professional communication skills of the engineers,

3. Professional communication training environment be organized in the engineering sites and projects,

4. Engineers be encouraged in making researches in their fields, and

5. Engineering resources including journals and periodicals be made available at work.

\section{REFERENCE}

Grünwald, N. (1999). Quo vadis German engineering education. Proc. 2nd Asia-Pacific Forum on Engineering Technology Education, 371-374.

Grünwald, N. a. (n.d.). The role of the European Union in fostering entrepreneurship education.

Jensen, H. (2000). Strategic planning for the education process in the next century. Global Journal of Engineering Education, 4(1), 35-42.

K.Latha. (2014). Role of English Language for Engineering students. AIJRHASS 14-566, 123.

Kitao, K. (1996)). Why do we teach English? The Internet TESL Journal, 2(4), 1-3.

Riemer, M. J. (2002). Global J. of Engng., 6(1).

Riemer, M. J. (2002). Global J. of Engng. Educ, 6(1).

Roulston, J. a. (1992). Educating engineers. what's happening to communication?, 190-193.

shrestha, A. (2011). Drama. India: XYZ publication centre.

Tattersall, I. (2000). Once we were not alone. Scientific American, 282(1), 38-44. 